\title{
IMPLOSIÓN EN EL IMPERIO
}

\section{IMPLOSION IN THE EMPIRE}

Guillermo Sullings: Economista y portavoz del Movimiento Humanista en Argentina

g.sullings@yahoo.com

\section{CURRÍCULUM VITAE}

Contador público, dirigente del Partido Humanista de Argentina, ex candidato presidencial del año 2003. Profesionalmente se desempeña desde el ño 1990 en Fiscalización del sistema de Obras Sociales, además del ejercicio libre de su profesión. Fundó la "Asociación Civil Generación Aconcagua". El 12 de agosto de 2004, funda y ejerce como Presidente de la "FUNDACIÓN PANGEA por una nación humana universal"

\section{RESUMEN}

El consumismo, la trampa del crédito y la avaricia financiera han producido el colapso del sistema. Es una enorme crisis financiera, con epicentro en EEUU pero con consecuencias en todo el mundo. El crédito es una trampa porque es un fenómeno mediante el cual se incentiva a las personas a anticipar el consumo mediante el endeudamiento. El mayor consumo genera un crecimiento de la economía real, y entonces la gente aumenta sus ingresos y puede afrontar mejor sus gastos y sus deudas. Este crecimiento siempre es menor que el del crédito y se generan las famosas burbujas. 


\title{
PALABRAS CLAVE
}

Consumismo - Crédito - Crisis - Consumo - Deuda

\begin{abstract}
Consumerism, the trap of credit and financial greed have led to the collapse of the system. It is a huge financial crisis, with its epicenter in the U.S. but worldwide consequences. Credit is a trap because it is a phenomenon by which encourages people to anticipate consumption through borrowing. The highest consumption growth generates the real economy, and then people can increase their income and better manage their expenses and debts. This increase is always smaller than the credit and the famous bubbles are generated.
\end{abstract}

\section{KEY WORDS}

Credit - Crisis - Consumer - Debt - Bubble

\section{TEXTO}

En estos días estamos asistiendo a la profundización de una enorme crisis financiera, con epicentro en EEUU pero con consecuencias en todo el mundo. En realidad esta crisis comenzó a mostrarse hace un año, pero ya se venía generando durante el 2006, y sus raíces son aún anteriores. Y bien podríamos decir que la "tierra fértil" para el desarrollo de tales raíces, se ha venido arando desde hace décadas. 
En el año 2000, cuando publicamos "Economía Mixta", dedicamos unos párrafos a lo que entonces denominamos "la trampa del crédito", como ese fenómeno por el cual se incentiva a las personas a anticipar el consumo mediante el endeudamiento. En un primer momento el nivel de consumo se incrementa (porque las personas gastan el equivalente a lo que ganan, más el equivalente a lo que se endeudan), y en un segundo momento su consumo baja porque los endeudados deben restringir sus gastos regulares, para generar un ahorro que les permita pagar lo que deben, más los intereses incorporados, que en el caso de créditos a largo plazo, pueden llegar a duplicar el valor de lo adquirido. Eso por una parte genera una transferencia de ingresos desde la economía productiva hacia la banca, y por otra parte genera ciclos de sucesivas expansiones y contracciones en la economía. Porque si bien cuando se expande el crédito, el mayor consumo genera un crecimiento de la economía real, y entonces la gente aumenta sus ingresos y se posiciona mejor para afrontar sus gastos y sus deudas, este ritmo de crecimiento real siempre es menor a la expansión del crédito, y se generan las famosas "burbujas", que indefectiblemente estallan.

Cuando hablamos de estos temas en "Economía Mixta", también hicimos mención al nivel de endeudamiento que ya entonces tenía la sociedad de EEUU, y mencionamos que en algún momento eso iba a estallar. Todo indica que ese momento se aproxima. No es nada fácil estimar los tiempos de estas cosas; cuando en 1998 anticipamos la caída de la convertibilidad en Argentina, podíamos realizar el análisis sobre una economía mucho más pequeña, más simple, y acotada a un solo país. La economía de EEUU en cambio, además de ser enormemente mayor y más compleja, ha tenido la posibilidad de "exportar" sus problemas, y habría que disponer de una cantidad descomunal de información a nivel mundial, para poder efectuar pronósticos más precisos. Pero no cabían dudas de que la tendencia era hacia una crisis cada vez más profunda. 
Antes de referirnos al detonante de la crisis actual, hay que entender como funciona la sociedad en EEUU con respecto al crédito, el consumo y la inversión especulativa. En ese país existe una cultura muy arraigada con respecto a endeudarse para trepar en el escalafón social (medido por el consumo). Y en aquellos que tienen capacidad de ahorro, existe una cultura muy difundida de invertir en acciones, fondos de inversión, y toda una serie de complejos instrumentos financieros, que aquí para el común de la gente ni se entiende de qué se trata. En EEUU la mayor parte de la población se endeuda para comprar artefactos del hogar, autos y casas; y cuando los termina de pagar vuelve a endeudarse para renovarlos. Los estudiantes universitarios se endeudan para pagar sus estudios y luego van pagando sus créditos cuando se reciben. Es una sociedad endeudada, al punto tal que en la actualidad, el nivel de endeudamiento medio de los hogares representa el $120 \%$ de sus ingresos anuales; o sea que en promedio, si los ciudadanos estadounidenses pudieran estar un año sin gastar un dólar, ni siquiera para comer, de todos modos deberían trabajar todo ese año y unos meses más para pagar lo que deben. Y el $75 \%$ de ese endeudamiento corresponde a deudas hipotecarias, detonante de la actual crisis. Pero ese nivel de endeudamiento de los ciudadanos de EEUU, no es solamente interno (entre ellos), sino que se viene financiando también con el enorme déficit que tiene ese país tanto en la balanza comercial, como en su balanza de pagos, ya que es el gobierno más endeudado del planeta. Entre China y Japón acumulan títulos de la deuda de EEUU por valor de casi 2 billones de dólares, debido a su superávit comercial con ese país.

Los antecedentes de la crisis actual

Dentro de ese contexto de una sociedad acostumbrada a endeudarse crecientemente, por una parte, y a generar burbujas de inversión por otra, es que comienza a gestarse la burbuja inmobiliaria entre el 2002 y el 2005. En esos tiempos la Reserva Federal había bajado las tasas para activar la economía, luego del impacto recesivo que 
generaron los temores a partir de los atentados del 11/09. Los bancos entonces podían endeudarse al $2 \%$ anual, y prestaban al $8 \%$ anual a quienes querían comprar o construir una casa. Era un gran negocio financiero por sí mismo, pero la voracidad de la banca no se conformaba con eso; para captar más y más clientes que sacaran su crédito hipotecario, relajaron las regulaciones y los controles y otorgaron créditos a personas de menor solvencia (hipotecas "subprime"), y fue el auge del negocio inmobiliario, que hizo subir y subir el precio de las propiedades. Pero a su vez, para poder prestar a cada vez más clientes, los bancos necesitaban captar fondos en el mercado, y entonces fue cuando comenzaron a ofrecer en garantía las mismas hipotecas que tenían en cartera de sus clientes. Hicieron eso una y otra vez, y las hipotecas pasaron a ser el soporte de toda una compleja trama de instrumentos financieros de los que llegaron a participar también bancos europeos...

Millones de ahorristas, a través de bancos, fondos de inversión, y empresas que cotizan en bolsa, financiaron el crecimiento de la burbuja, la mayoría de las veces sin saber cuál era la garantía final de su inversión. Todo esto con la anuencia de las prestigiosas calificadoras de riesgo que tanto se han ocupado de descalificar a las economías emergentes, y nunca previnieron a los ahorristas sobre el riesgo de estos irracionales instrumentos de crédito del primer mundo. $\mathrm{Y}$ todo fue un negocio próspero mientras las propiedades subían de valor y la rueda del endeudamiento y el pago de las cuotas seguía funcionando. Pero como toda burbuja un día estalló.

La Reserva Federal comenzó a aumentar las tasas hasta superar el 5 \% para contener la inflación, y entonces los bancos también aumentaron las tasas de los créditos hipotecarios ya otorgados (que son a tasa variable). Mientras tanto muchos propietarios que no eran demasiado solventes, ya habían empezado a entrar en mora; pero al aumentar las tasas la mora se multiplicó y ya en el 2006 hubo 1.200.000 ejecuciones hipotecarias. El valor de las propiedades, que había llegado a niveles irracionales, comenzó a desinflarse, primero por una lógica de valores relativos, pero 
ese desinfle se aceleró cuando muchos propietarios pusieron en venta sus casas porque no podían pagar las cuotas de su hipoteca. Esta baja en las propiedades hizo que muchos propietarios tuvieran con el banco una deuda mucho mayor al valor de su casa, por lo cual también la pusieron en venta, con lo cual los valores siguieron bajando. Al día de hoy se estima que más de 5.000.000 de familias tienen en venta su casa porque no pueden pagar la hipoteca, y hay 2.000.000 que están por perderla en una ejecución.

Cuando estalló la crisis en agosto del 2007, se estimaba que había una morosidad acumulada de más de 500.000 millones de dólares en el mercado de las hipotecas. Pero mucho mayor era la pérdida de valor de los títulos y acciones que estaban respaldados por las entonces bautizadas "hipotecas basura". En otras palabras, muchos de los bancos vinculados al negocio inmobiliario no pudieron afrontar sus deudas porque se evaporaron sus activos, apalancados en hipotecas incobrables y devaluadas. Y en esa compleja trama financiera, el efecto dominó empezó a arrastrar a la quiebra a muchas entidades relacionadas de algún modo con estos instrumentos financieros apoyados en una frágil burbuja. Los casos más resonantes fueron Freddie Mac, Fannie Mae, Bearns Stearns, y más recientemente Lehman Brothers y AIG, pero hubo un centenar de entidades afectadas en USA y algunas en Europa que tuvieron que ser apuntaladas.

Y este efecto dominó ya tiene un año, y aún no llegó a su fin. El gobierno de EEUU y la Reserva Federal inyectan cientos de miles de millones para morigerar el terremoto, pero nunca es suficiente, y la crisis en las hipotecas contaminó a todo el mercado financiero y bursátil. Los inversores sacan el dinero de los bancos y fondos de inversión por pánico y desconfianza, y con ello debilitan aún más al sistema financiero. Los tenedores de bonos o acciones tratan de venderlos para hacerse de efectivo, o porque prevén una mayor depreciación de los mismos, y al hacerlo, más se deprecian. O sea, se está pasando de la dimensión del problema hipotecario (de 
por sí enorme), a la dimensión de la profecía auto cumplida de una corrida bancaria y bursátil que genera quiebras en cadena. $\mathrm{Y}$ ese es el problema que hoy enfrenta EEUU. 